\title{
UNCERTAINTY AND SENSITIVITY ANALYSIS OF TMI-2 ACCIDENT SCENARIO USING SIMULATION BASED TECHNIQUES
}

\author{
R. SRINIVASA RAO ${ }^{1 * a}$, ABHAY KUMAR ${ }^{2}$, S.K. GUPTA ${ }^{1}$, and H.G. LELE ${ }^{3}$ \\ ${ }^{1}$ Nuclear Safety Analysis Division, Atomic Energy Regulatory Board, Anushaktinagar, Mumbai-400094, India \\ ${ }^{2}$ Light Water Reactor Division, Bhabha Atomic Research Centre, Mumbai, India \\ ${ }^{3}$ Reactor Safety Division, Bhabha Atomic Research Centre, Mumbai, India \\ ${ }^{*}$ Corresponding author. E-mail : srini@aerb.gov.in
}

Received July 12, 2011

Accepted for Publication December 20, 2011

The Three Mile Island Unit 2 (TMI-2) accident has been studied extensively, as part of both post-accident technical assessment and follow-up computer code calculations. The models used in computer codes for severe accidents have improved significantly over the years due to better understanding. It was decided to reanalyze the severe accident scenario using current state of the art codes and methodologies. This reanalysis was adopted as a part of the joint standard problem exercise for the Atomic Energy Regulatory Board (AERB) - United States Regulatory Commission (USNRC) bilateral safety meet.

The accident scenario was divided into four phases for analysis viz., Phase 1 covers from the accident initiation to the shutdown of the last Reactor Coolant Pumps (RCPs) (0 to $100 \mathrm{~min}$ ), Phase 2 covers initial fuel heat up and core degradation (100 to $174 \mathrm{~min}$ ), Phase 3 is the period of recovery of the core water level by operating the reactor coolant pump, and the core reheat that followed (174 to $200 \mathrm{~min}$ ) and Phase 4 covers refilling of the core by high pressure injection (200 to $300 \mathrm{~min}$ ).

The base case analysis was carried out for all four phases. The majority of the predicted parameters are in good agreement with the observed data. However, some parameters have significant deviations compared to the observed data. These discrepancies have arisen from uncertainties in boundary conditions, such as makeup flow, flow during the RCP 2B transient (Phase 3), models used in the code, the adopted nodalisation schemes, etc. In view of this, uncertainty and sensitivity analyses are carried out using simulation based techniques. The paper deals with uncertainty and sensitivity analyses carried out for the first three phases of the accident scenario.

KEYWORDS : TMI-2, SCDAP, Severe Accident, Uncertainty, Sensitivity

\section{INTRODUCTION}

Uncertainty analysis and sensitivity (importance) analysis are essential parts of complex systems. Specifically, uncertainty analysis refers to the determination of the results that derive from uncertainty in models, representation uncertainties and input parameters, while sensitivity analysis refers to the determination of the contributions of individual inputs to the uncertainty in analysis results. The uncertainty under consideration here is often referred to as epistemic uncertainty; alternative designations for this form include state of knowledge, subjective, reducible,

\footnotetext{
${ }^{a}$ Corresponding author at: Nuclear Safety Analysis Division, Atomic Energy Regulatory Board,

Mumbai, 400094, India

Tel.: +91-22-25990468, Fax: +91-22-25990499

Email address: $\underline{\text { srini@ aerb.gov.in }}$
}

and type B. Epistemic uncertainty derives from a lack of knowledge about the appropriate value to use for a quantity that is assumed to have a fixed value in the context of a particular analysis. In the conceptual and computational organization of an analysis, epistemic uncertainty is generally considered to be distinct from aleatory uncertainty, which arises from an inherent randomness in the behaviour of the system under study. Alternative designations for aleatory uncertainty include variability, stochastic, irreducible, and type A [1].

Sources of uncertainties could be broadly classified into the following general categories [2]:

(a) Code or model uncertainties: A thermal-hydraulic system code is a computational tool that typically includes three different sets of balance equations (or of equations derived from fundamental principles), closure or constitutive equations, material and state properties, special process or component models, and a numerical solution method. The interfacial drag 
coefficient, wall to fluid friction factor and heat transfer coefficient are typically expressed by constitutive equations. Various sets of material properties are embedded into the codes, even though the user may change these properties or add new materials.

(b) Representation uncertainties: Representation uncertainty is related to the process of setting up the nodalization (idealization). The nodalization constitutes the connection between the code and the 'physical reality' that is the subject of the simulation.

(c) Scaling uncertainty: Using data recorded in scaled experiments and the reliance on scaling laws to apply the data results to full scale systems. Owing to limitations of the fundamental equations at the basis of system codes, the scaling issue may constitute a source of uncertainties in code applications and may envelop various individual uncertainties.

(d) Plant uncertainty: Uncertainty or limited knowledge of boundary and initial conditions, and related values for a particular nuclear power plant are referred to as plant uncertainty. Typical examples are the pressurizer level at the start of the transient, the thickness of the gap of the fuel rod, the conductivity of the $\mathrm{UO}_{2}$, and the gap between the pellets and the cladding.

(e) User effect: The flexibility of the system codes for various volume control flags, junction control flags, solution methods, etc. under consideration is a primary reason for generating a user effect. The impact of the user effect upon the final result may be different depending upon the selected uncertainty method. System code output results are largely affected by a user's capability, qualifications and experience in the use of the code. It has been observed that results obtained by various users differ, despite using the same system code and same data provided for the modeling.

User effects and scaling uncertainties were not considered in the present work. The user guidelines for development of the nodalisation were followed, therefore representation uncertainty is also not considered in the present work.

A number of approaches to uncertainty and sensitivity analyses have been developed, including differential analysis, response surface methodology, Monte Carlo analysis, and variance decomposition procedures. Monte Carlo (i.e., simulation based) approaches to uncertainty and sensitivity analysis are used in the present study. Simulation based approaches to uncertainty and sensitivity analyses are effective and widely used.

The uncertainties involved in severe accident analyses are significantly larger than those involved in design basis accident analyses. This is because of immaturity in the understanding and modeling of the phenomena, development of computer codes and estimation of material properties. As the TMI-2 severe accident scenario is very complex in nature, uncertainties exist in many aspects, which include initial and boundary conditions, models used in codes to represent the phenomenological aspects in both thermal hydraulics and core degradation, especially in melt pool formation and relocation, etc. The uncertainty analysis helps in improving the code models and their parameters. This approach can identify the key parameters, which can have significant contribution to the overall uncertainties.

This methodology consists of selection and characterization of uncertainty of input parameters, generation of samples and the propagation of sampled inputs through an analysis. In this analysis 10 key input parameters were selected based on engineering judgement, code defaults and literature. The probability density function of uniform distribution is used to represent uncertainties. These uncertainties are propagated through simulation approach using Latin Hypercube Sampling (LHS) technique to generate a sample (sample size of 50) and corresponding code calculations were performed. Also a separate code calculation was performed for the median inputs. Mean, median, 5th and 95th percentile values were estimated for key figures of merit. The standardized rank regression co-efficients and partial rank correlation co-efficients were estimated to see the sensitivity of the various parameters to the selected figures of merit. The coefficient of determination $\left(\mathrm{R}^{2}\right)$ was estimated to see the goodness of fit.

Three Mile Island Unit 2 (TMI-2) was a Babcock and Wilcox (B\&W) designed Pressurized Water Reactor (PWR) operated by General Public Utilities. The accident at TMI-2, which resulted in severe damage to the reactor core and associated structures, began on Wednesday, March 28, 1979, at 4:00:37 in the morning [3]. The accident started with a loss of main feedwater to both once-through steam generators (OTSG). This loss of heat sink came about when the main feedwater pumps (MFP) lost suction due to a loss of both condensate pumps. Subsequently, the main turbine tripped and the auxiliary feedwater pumps (AFWP) automatically started to operate as designed. However, the AFW could not be injected to either OTSG because the AFW system block valves (EFV12A and EF-V12B) were in the closed position.

The loss of heat sink resulted in a rapid depletion of the OTSG inventory, which subsequently led to rapid primary system pressure increase and opening of the pressurizer Electromatic Relief Valve (ERV) (also known as the pilot operated relief valve or PORV). The high primary system pressure automatically initiated a reactor signal that caused reactor shutdown, which in turn resulted in a rapid reduction in the primary system pressure. The reduction in the primary system pressure should have caused the closure of the PORV; however, this valve failed in a stuck-open position (i.e., causing continued loss of coolant inventory). Without AFW the OTSGs boiled dry in about 1.5 minutes. At 8 minutes the AFW block valves were opened and measurable levels were 
reestablished in the OTSGs by $\sim 25$ minutes. By the time the AFW injection was started, both primary hot legs had reached saturation condition, which continued until about 74 minutes when the B loop reactor coolant pumps (RCPs) were shut down to avoid cavitation. Subsequently, at about 100 minutes, the A loop RCPs were also de-energized to prevent cavitation. At this time, the primary system inventory was for the most part depleted, and shortly after the final RCP trip, both hot leg temperatures increased above saturation, which was indicative of steam superheating due to excessive core heatup. At about 139 minutes the PORV block valve was closed and the loss of coolant through this path was terminated.

At 174 minutes the RCP 2B was started, and then stopped at 193 minutes due to zero flow and low motor current. At 200 minutes, makeup flow greatly increased by operating pumps $1 \mathrm{~A}$ and $1 \mathrm{C}$ for a short period of time. The operator switched off pumps $1 \mathrm{~A}$ and $1 \mathrm{C}$ due to low levels in the Borated Water Storage Tank (BWST) for 5 minutes. At about 262 and 267 minutes, make up pumps $1 \mathrm{~B}$ and $1 \mathrm{C}$ were put into continuous operation. It is generally believed that the reactor was refilled by 300 minutes, at which point the accident was in the recovery phase. Reference 3 provides the plant data used for this analysis.

The severe accident computer code SCDAP/RELAP5 /MOD3.2 was used to perform analyses. The code has been developed for best-estimate transient simulation of water reactor coolant systems during severe accidents. USNRC peer review committee reviewed the technical adequacy of the various models of the code, and brought out important inadequacies in the models. The committee found that many code models were technically adequate during the early intervals of an accident, but were deemed inadequate as an accident progressed into the later intervals, where core degradation, relocation and possible vessel failure might occur. Models such as fuel-rod liquefaction, flow and solidification; fission product release, transport and deposition; control rod and core structure including grids; debris heat-up; heat transfer; fragmentation and quenching in the core and lower plenum; molten pool formation, crust behavior and convection in molten pools; and heat transfer to lower head and vessel-head response were found to be technically inadequate [4]. Although, the code subsequently underwent changes, there are possibilities of uncertainties, as the severe accident phenomena are still not well understood.

\section{APPROACH}

The simulation based (Monte Carlo) approach involves the generation and exploration of a mapping from uncertain analysis inputs to uncertain analysis results. The underlying idea is that analysis results (figures of merit) $\mathbf{y}(\mathbf{x})=\left[\mathrm{y}_{1}(\mathbf{x})\right.$, $\left.\mathrm{y}_{2}(\mathbf{x}), \ldots \mathrm{y}_{\mathrm{nY}}(\mathbf{x})\right]$ are functions of uncertain analysis inputs $\mathbf{x}=\left[\mathrm{x}_{1}, \mathrm{x}_{2}, \ldots \mathrm{x}_{\mathrm{nX}}\right]$. In turn, uncertainty in $\mathbf{x}$ results in a corresponding uncertainty in $\mathbf{y}(\mathbf{x})$. This leads to two questions: (i) what is the uncertainty in $\mathbf{y}(\mathbf{x})$ given the uncertainty in $\mathbf{x}$ and (ii) how important are the individual elements of $\mathbf{x}$ with respect to the uncertainty in $\mathbf{y}(\mathbf{x})$ ? The goal of uncertainty analysis is to answer the first question, and the goal of sensitivity analysis is to answer the second question. In practice, the implementation of an uncertainty analysis and sensitivity analysis are very closely connected on both a conceptual and a computational level. The methodology adopted for the present study consists of the following steps [5]:

(i) Selection of input parameters

(ii) Characterisation of uncertainty

(iii) Propagation of uncertainties

(iv) Assessment of uncertainties in key figures-of-merit relative to observations at TMI-2, and Sensitivity/ Importance analysis.

\subsection{Selection of Input Parameters}

The key input parameters, which have significant impact on the required figures-of-merit, were selected based on the expert judgment, code defaults and literature survey $[5,6]$. Ten key parameters were selected, which include a make-up flow and other model parameters.

(i) Make-up Flow Rate during 100 - 200 min - The combined make-up and High Pressure Injection (HPI) flow rate in the base case analysis is $2.1 \mathrm{~kg} / \mathrm{s}$. The range of this parameter is selected to be $2.0-3.0 \mathrm{~kg} / \mathrm{s}$ for the present study. Initially the range of the parameters were selected to be $2.0-4.0 \mathrm{~kg} / \mathrm{s}$ and modified to the above range after some initial screening analysis as mentioned below.

(ii) PORV Co-efficient of Discharge - The models used in RELAP5 predict that the flow under sub-cooled conditions is as much as $20 \%$ larger, and under low quality saturated conditions, the flow is little as $20 \%$ lower. Also, loss of coolant through the Pilot Operated Relief Valve (PORV) has been selected as one of the parameters, due to having large uncertainties. Initially the lower limit of this parameter was fixed at 0.92 . However, the combinations of the lower limit of this parameter and the upper limits of the make-up flow rate resulted in more water inventory in Reactor Pressure Vessel (RPV) and cooling of core, which led to de-pressurisation of the RPV in many cases, instead of re-pressurisation found in the initial screening analysis. Therefore, the lower range of this parameter is restricted to 0.95 . The base case results with a co-efficient of discharge of 1.0 showed that the total cumulative flow is larger than the actual value (plant data); hence the upper range of the parameter is fixed at 1.0.

(iii) Failure Temperature of Oxide Shell - Temperature at which the fuel rod oxide shell fails provided that the extent of oxidation is less than the durability threshold. If the cladding surface temperature is less than this temperature, the oxide shell does not fail. The code default value 
is $2500 \mathrm{~K}$. As the oxide failure temperature is increased, cladding oxidation increases over a long period of time. The SCDAP model LIQSOL oxide-shell failure criteria are based on achieving either a user specified failure temperature and cladding oxide fraction, or an oxide shell melting temperature. The amount of relocation can be very sensitive to the choice of oxide shell breach temperature. These parametric fuel rod failure criteria are expected to dominate the SCDAP predictions of fuel failure conditions during severe accidents. This is probably the most important uncertainty associated with the early melt progression and fission product release, where the SCDAP models are inadequate [7]. The range of the parameter is selected to be $2300-2650 \mathrm{~K}$ based on the values used to simulate various test problems including CORA, FLHT, etc. The lowest oxide failure temperature predicts the smallest amount of hydrogen, whereas the highest oxide failure temperature predicts the largest amount of hydrogen generation. As the oxide failure temperature is increased, cladding oxidation increases over a long period of time.

(iv) Durability Index - The fraction of oxidation required before the oxide layer is durable for temperatures above the user defined failure temperature of the oxide shell. The durability threshold for the oxide shell was assigned a value of 0.2 in the base case calculation, which is the default value for analysis of a nuclear power plant. The value of 0.6 is the default value for analysis of severe accident experiments. The value of 0.6 represents a lower bound value of oxide strength for analysis of a nuclear power plant. In the present study, the lower bound of this parameter is selected as 0.2 and a value of 0.6 is used as the upper bound, to characterize the uncertainty.

(v) Porosity of Particulate Debris - The thermal shocking by reflood water of a reactor core embrittled by oxidation results in the formation of porous debris. The porous debris resulting from the degradation of fuel rods into particles is characterized by porosity and particle size. Experimental results indicate that the porosity and particle size are a function of the maximum temperature of the fuel during the damage progression period before quenching. The upper bound of the value is fixed at the code default value of 0.54 and the lower range of the value used is 0.25 , which is the same value used in MELCOR calculations [6]. (vi) Particle Diameter - As mentioned above, the diameter of the particles of debris is also a function of the maximum temperature of the fuel during the damage progression period before quenching. The default value of the code is $0.00087 \mathrm{~m}$ and this value is used as a lower bound. The upper bound is fixed at 0.1 , which is the same value used in MELCOR calculations [6].

(vii) Hoop Strain Threshold for Double Sided Oxidation - The ballooning of fuel rod cladding, and the time and location of cladding rupture can have a significant impact on the progression of damage in a reactor core during a severe accident. Several phenomena that may occur during a severe accident are influenced by cladding ballooning and rupture. If cladding is calculated to balloon and rupture, the heatup due to oxidation may be a factor of 2.6 times larger than before ballooning and rupture. The degree of the fuel rod cladding (double-sided versus single-sided oxidation) and the structural behaviour of the cladding oxide shell have a significant impact on early phase damage progression. Since these areas of behaviour are calculated using empirical models, it is important that a broad range of experiments be used to define the values of the parameters in these empirical models. Examples of these parameters are (a) extent of oxidation of fuel rod cladding that results in an oxide shell that does not breach until it begins to melt, and (b) minimum hoop strain of cladding at a location for double-sided oxidation to occur at that location. The empirical models are used for calculating these quantities. The default value used in the code is 0.07 . The range of 0.02 to 0.07 is used in the present study. The range selected is based on code defaults and various values used for different test problems and experiments.

(viii) Fraction of Surface Area Covered with Drops of Relocated Material - This is the threshold value of the fraction of the surface area covered with drops of relocated material that results in local blockage that stops the oxidation of the drops. On the basis of severe fuel damage experiments, this user-defined variable is recommended to have a value between 0.2 and 0.5 . The code default value is 0.2 . However, a range of 0.2 to 0.4 is used in the present study based on the values used in various experiments and studies.

(ix) Hoop Strain at which Rupture of Fuel Cladding Occurs - The default value for this parameter is 0.18 . The range of 0.15 to 0.18 is selected based on various experiments [5].

(x) Transition Strain - This is the hoop strain at which transition from sausage type deformation to localized deformation occurs. The default value for this parameter is 0.20 . The range of 0.18 to 0.20 is selected based on various experiments [5].

\subsection{Characterisation of Uncertainty}

The uncertainty of key input parameters characterised by defining distributions is the most important part of a simulation-based uncertainty and sensitivity analysis, as these distributions determine both the uncertainty in figuresof-merit and the sensitivity of the figures-of-merit to the key input parameters/model parameters.

Ten key input parameters and their ranges were selected based on the extensive literature survey, code defaults and expert judgement. The uncertainty in these parameters is characterized by the uniform distribution in the present study. In the absence or lack of data, a uniform distribution is assigned to each parameter for characterization of uncertainty. The input/model parameters and its ranges are shown in Table 1. 
Table 1. Input Parameters, Their Ranges and Distributions

\begin{tabular}{|c|c|c|c|c|}
\hline Parameter & Lower bound & Median & Upper bound & Distribution \\
\hline Makeup flow rate during 100-200 $\mathrm{min}(\mathrm{kg} / \mathrm{s})$ [X1] & 2 & 2.5 & 3 & Uniform \\
\hline PORV discharge co-efficient [X2] & 0.95 & 0.975 & 1 & Uniform \\
\hline Failure temperature of oxide shell $(\mathrm{K})[\mathrm{X} 3]$ & 2300 & 2475 & 2650 & Uniform \\
\hline Durability index [X4] & 0.2 & 0.4 & 0.6 & Uniform \\
\hline Porosity of debris [X5] & 0.25 & 0.395 & 0.54 & Uniform \\
\hline Particle diameter (m) [X6] & 0.00087 & 0.05 & 0.1 & Uniform \\
\hline Hoop strain threshold for double sided oxidation [X7] & 0.02 & 0.045 & 0.07 & Uniform \\
\hline $\begin{array}{l}\text { Fraction of surface area covered with drops that result in } \\
\text { blockage that stops local oxidation of drops [X8] }\end{array}$ & 0.2 & 0.3 & 0.4 & Uniform \\
\hline Hoop strain at which rupture of fuel cladding occurs [X9] & 0.15 & 0.165 & 0.18 & Uniform \\
\hline $\begin{array}{c}\text { Hoop strain at which transition from sausage type deformation } \\
\text { to localized deformation occurs [X10] }\end{array}$ & 0.18 & 0.19 & 0.20 & Uniform \\
\hline
\end{tabular}

\section{PROPAGATION OF UNCERTAINTIES}

A simulation method is used for the propagation of uncertainties in the present study. Several sampling strategies are available, including random sampling, importance sampling and Latin hypercube sampling (LHS) [8]. LHS is very popular for use with computationally demanding models, because its efficient stratification properties allow for the extraction of a large amount of uncertainty and sensitivity information, with a relatively small sample size. The LHS method consists of three steps to obtain an $\boldsymbol{n} \boldsymbol{X} \boldsymbol{k}$ design matrix, where $\mathrm{n}$ is the planned number of code runs and $\mathrm{k}$ is the number of input variables. The first step is dividing each input variable $\boldsymbol{X}_{\boldsymbol{i}}(\boldsymbol{i}=\boldsymbol{1}$ to $\boldsymbol{k})$ into $\boldsymbol{n}$ intervals with equal probability of $1 / \boldsymbol{n}$. The second step is obtaining $\boldsymbol{X}_{i j}(\boldsymbol{j}=\boldsymbol{1}$ to $\boldsymbol{n})$ for each input variable $X_{\mathrm{i}}$. The third step is random coupling of $\boldsymbol{X}_{i j}(\boldsymbol{j}=\boldsymbol{1}$ to $\boldsymbol{n}, \boldsymbol{i}=\boldsymbol{1}$ to $\boldsymbol{k}$ ). Ref. 2 and 3 suggest that the sample size is greatly reduced if the LHS technique is used for generating the sample. The number of Latin hypercube samplings for $\mathrm{k}$ input variables are sufficient if they are 4/3k [4]. However, it would be better to obtain as many samples as possible ( $2 \boldsymbol{k}$ to $5 \boldsymbol{k}$ ). In this study, 50 computer code runs were performed for 10 input parameters, which are considered to be adequate.

\section{RESULTS OF UNCERTAINTY ANALYSIS}

The results of the uncertainty analysis are presented in the form of mean, median, $5^{\text {th }}$ and $95^{\text {th }}$ percentile values. The median value is the middle value of the $\mathrm{N}$ ordered values (ascending order). The $5^{\text {th }}$ and $95^{\text {th }}$ percentiles are calculated using the following equation. The $\mathrm{p}^{\text {th }}$ percentile of $\mathrm{N}$ ordered values is obtained by first calculating the rank (r) using the following equation, rounding to the nearest integer, and taking the value which corresponds to the calculated rank.

$$
\mathrm{r}=\mathrm{N} / 100 *(\mathrm{p})+1 / 2
$$

The time history of primary pressure, cumulative mass flow through PORV, pressuriser water level, structure temperatures near RPV and SG for both hot legs, RPV water level, and mass of hydrogen generation are shown in Figures 1 through 9 respectively. The plant data are also plotted in the same figures, except for RPV water level and mass of hydrogen. A separate code calculation was performed using median inputs, the results of which are also plotted. The mean, median $\left(50^{\text {th }}\right), 5^{\text {th }}$ and $95^{\text {th }}$ percentiles are computed from 50 runs for each parameter, and are shown in figures. Although the base calculation was performed up until 300 minutes of the accident scenario, the uncertainty analysis was performed only up to 200 minutes. One out of fifty calculations failed at about 194.3 minutes, due to non-convergence of the solution. The trend of the results similar to the failed run was picked from the other 49 runs, and is extended up to 200 minutes, to work the computer programs developed. It does not have any impact on the figures-of-merit, as their parameter timings are selected at less than 194 minutes. The total amount of hydrogen generation at the end of the calculation (200 minutes) will not be affected, as the hydrogen generation becomes almost saturated by this time. 
Figure 1 shows the time history of the primary pressure. The measured value is very well predicted between the lower and upper bounds of the $5^{\text {th }}$ and $95^{\text {th }}$ percentile values up to 139 minutes, irrespective of the differences in input parameters, except during the initial period between 5 to 20 minutes. Later $5^{\text {th }}$ and $95^{\text {th }}$ percentile values encompass the plant data up to about 175 minutes. Here, the $95^{\text {th }}$ percentile value is very close to the plant data compared to the median inputs. Pump seal leak is not considered in the analysis, which varies from $0-2 \mathrm{~kg} / \mathrm{s}$, resulting in the cooling and de-pressurisation of RPV instead of repressurisation, as shown in some of the cases. Perhaps the plant data could have been encompassed by the $5^{\text {th }}$ and $95^{\text {th }}$ percentiles even after 175 minutes, had pump seal leak been considered. The mean and median values of the 50 runs are in agreement with the plant data up to 139 minutes. However, they are under-predicted after 139 minutes.

The time history of cumulative mass flow through PORV is shown in Figure 2. The predicted cumulative mass flow rate through PORV is higher for all cases, such

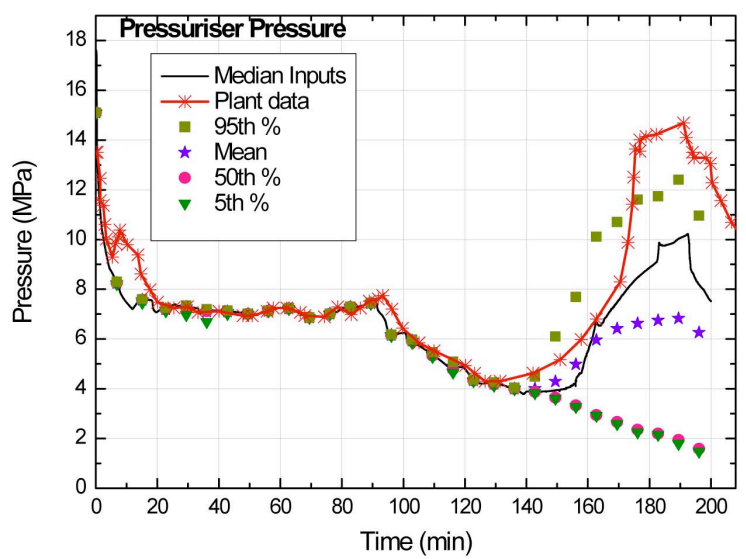

Fig. 1. Pressuriser Pressure

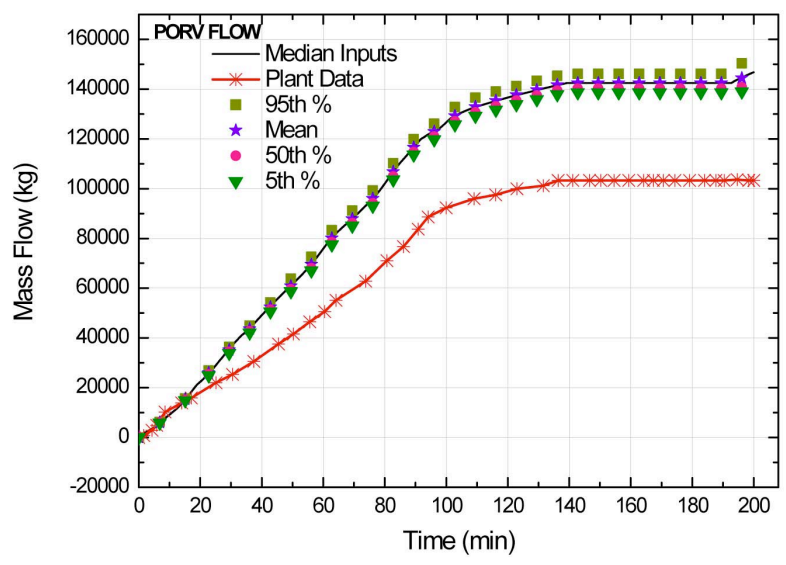

Fig. 2. PORV Cumulative Flow as median inputs, mean, and $5^{\text {th }}, 50^{\text {th }}$ and $95^{\text {th }}$ percentiles, compared to the plant data, as was predicted in the base case with a make-up flow rate of $2.1 \mathrm{~kg} / \mathrm{s}$ and PORV discharge coefficient of 1.0. Again this could be due to omission of pump seal leak.

Figure 3 shows the time history of the pressuriser water level during the accident scenario. Again the error bands are very close, up to about 139 minutes. After 139 minutes, the $95^{\text {th }}$ percentile value is very close to the plant data; however the plant data is not in the error bands. The pressuriser water level prediction after 139 minutes significantly improved in the base case results, before performing the uncertainty analysis, after incorporation of suggestions like counter current flow limitation models (CCFL), introducing a small horizontal portion in the surge line as per the actual geometry etc. as mentioned in References 6 and 7.

Figures 4 through 7 show the structure temperatures of loop A and B's hot legs, near SG and RPV, respectively. The plots indicate median inputs, plant data, and $95^{\text {th }}$, mean, $50^{\text {th }}$ and $5^{\text {th }}$ percentile values. The structure temperatures

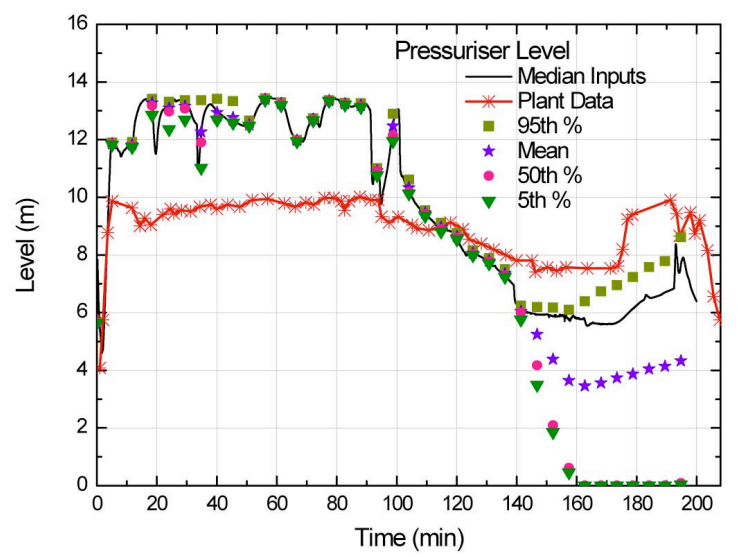

Fig. 3. Pressuriser Water Level

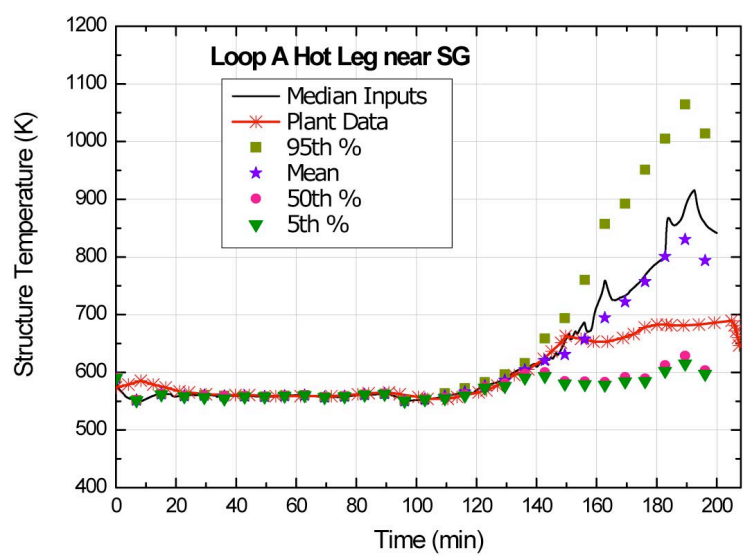

Fig. 4. Loop A Hot Leg Structure Temperature Near SG 
are compared with the plant data, whereas in the base case (discussed in earlier sections) the plant data was compared with the fluid temperature. It may be noted that the instrumentation used to measure the fluid temperature had a limitation of measuring high temperatures. The calculated structure temperatures at near SG and RPV in both hot legs are more or less in the error band of $5^{\text {th }}$ and $95^{\text {th }}$ percentile values.

Figure 8 shows the time history of the RPV water level during the accident scenario. The plot shows the calculated values of the median inputs, and the $95^{\text {th }}$, mean, $50^{\text {th }}$ and $5^{\text {th }}$ percentiles. The plant data is not available for comparison. The error band between $5^{\text {th }}$ and $95^{\text {th }}$ percentile values up to 150 minutes is negligible. Later, the error band is increased.

Figure 9 shows the time history of hydrogen generation during the accident scenario. Again the time history of the plant data is not available for comparison, however $300 \mathrm{~kg}$ of hydrogen up to 174 minutes, and $460 \mathrm{~kg}$ of hydrogen up to 200 minutes were estimated based on some measurements. The plot shows calculated values of the

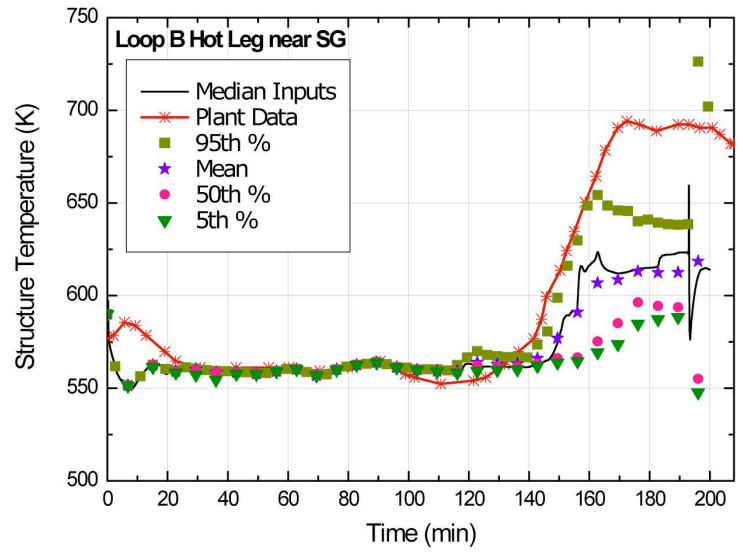

Fig. 5. Loop B Hot Leg Structure Temperature Near SG

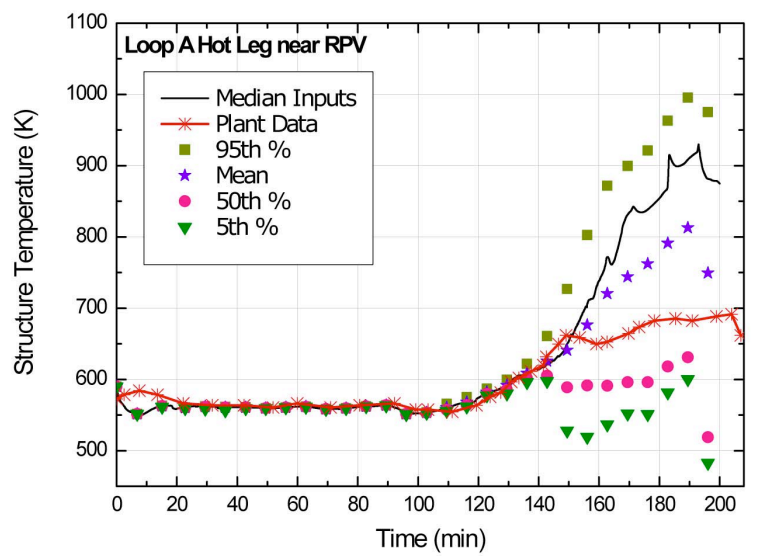

Fig. 6. Loop A Hot Leg Structure Temperature Near RPV median inputs, $95^{\text {th }}$, mean, $50^{\text {th }}$ and $5^{\text {th }}$ percentiles. The total hydrogen generation for the $95^{\text {th }}$ percentile case was

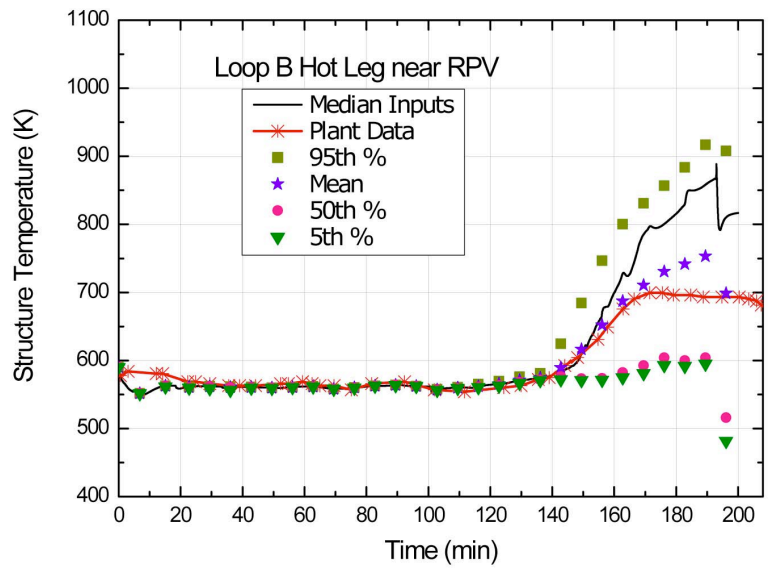

Fig. 7. Loop B Hot Leg Structure Temperature Near RPV

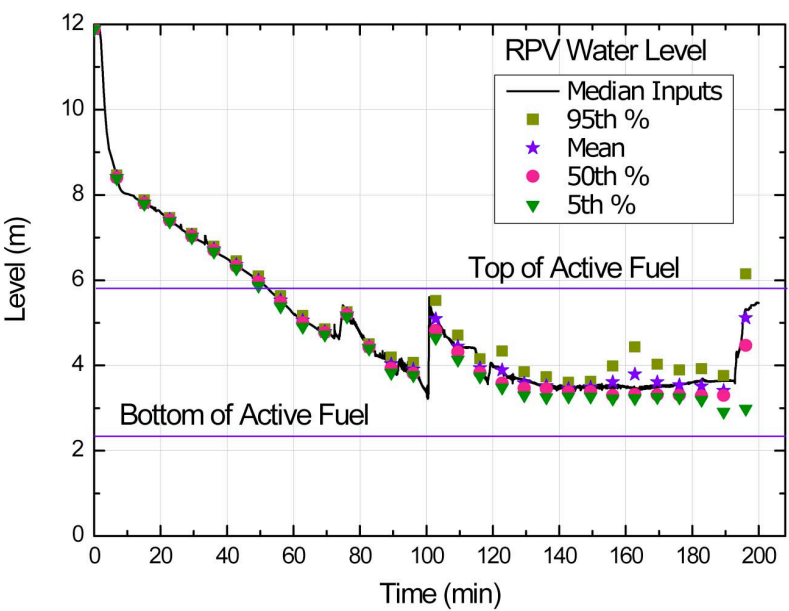

Fig. 8. RPV Water Level

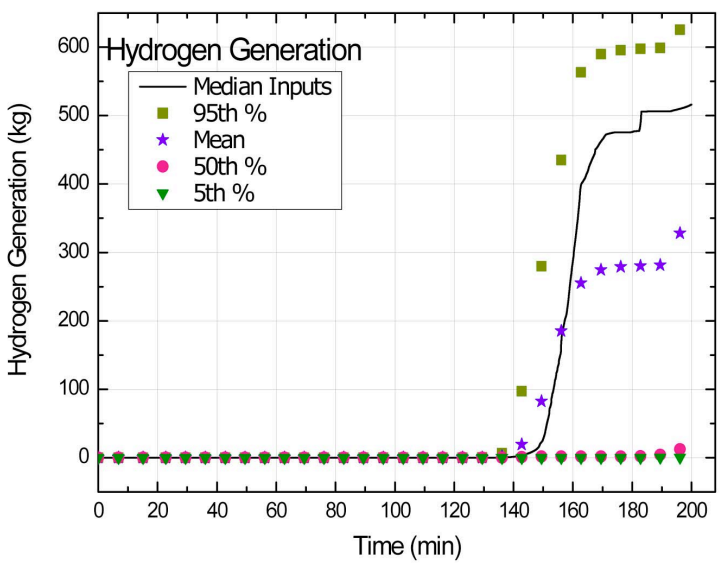

Fig. 9. Hydrogen Generation 
about $600 \mathrm{~kg}$ in 200 minutes, whereas about $510 \mathrm{~kg}$ of hydrogen was generated in the median inputs. The mean value shows about $320 \mathrm{~kg}$ of hydrogen generation during the accident scenario up to 200 minutes. Also, an amount of $600 \mathrm{~kg}$ of hydrogen was generated in 200 minutes in the base case.

\section{SENSITIVITY/IMPORTANCE ANALYSIS}

Many authors, when referring to the degree to which an input parameter affects the model output, use 'sensitive', 'important', 'most influential', 'major contributor', 'effective' or 'correlated' interchangeably [9]. Determination of sensitivity/importance analysis results is usually more demanding than the presentation of uncertainty analysis results due to the need to actually explore the mapping $\left[x_{i}, y\left(x_{i}\right)\right], \mathrm{i}=1$ to $\mathrm{N}$ to assess the effects of individual elements of $\boldsymbol{y}$. A number of approaches to sensitivity analysis that can be used in conjunction with a sampling based uncertainty analysis are available. The regression analysis and partial correlation are used to determine the importance analysis results in the present study.

\subsection{Regression analysis}

Regression analysis provides an algebraic representation of the relationships between $y$ and one or more of the $\boldsymbol{x}_{j}$ 's. In the present study the linear relationship between $\mathrm{y}$ and $\boldsymbol{x}_{j}{ }^{\prime}$ s is assumed. For multiple independent variables the linear regression model can be expressed as

$$
\hat{y}=b_{0}+\sum_{j=1}^{n X} b_{j} x_{j}
$$

where:

$\mathrm{nX}=$ number of uncertain input parameters

$\mathrm{b}=$ regression co-efficients

The regression co-efficients $\boldsymbol{b}_{j}, \mathrm{j}=1$ to $\mathrm{nX}$ are not very useful in sensitivity analysis, because each bj is influenced by the units in which $\mathrm{xj}$ is expressed, and also does not incorporate any information on the distribution assigned to $\underline{\boldsymbol{x}}_{\text {. }}$. Because of this, the regression models in Eq. 2 are usually reformulated as

$$
(\hat{y}-\bar{y}) / \hat{s}=\sum_{j=1}^{n X}\left(b_{j} \hat{s}_{j} / \hat{s}\right)\left(x_{j}-\bar{x}_{j}\right) / \hat{s}_{j}
$$

where:

$$
\begin{aligned}
& \hat{s}=\left[\sum_{i=1}^{n S}\left(y_{i}-\bar{y}\right)^{2} /(n S-1)\right]^{1 / 2}, \\
& \hat{s}_{j}=\left[\sum_{i=1}^{n S}\left(x_{i j}-\bar{x}_{j}\right)^{2} /(n S-1)\right]^{1 / 2} \\
& \bar{x}_{j}=\sum_{i=1}^{n S} x_{i j} / n S \text { and } \bar{y}=\sum_{i=1}^{n S} y_{i} / n S
\end{aligned}
$$

The coefficients $b_{j} \hat{\boldsymbol{S}}_{j} / \hat{\mathrm{S}}$ in Eq. 3 are referred to as standardised regression coefficients (SRCs). The SRCs provide a useful measure of variable importance with (i) the absolute values of the coefficients providing a comparative measure of variable importance (i.e., variable $\mathrm{x}_{\mathrm{u}}$ is more important than variable $\mathrm{x}_{\mathrm{v}}$ if $\left|b_{u} \hat{\mathrm{S}}_{u} / \hat{\boldsymbol{S}}\right|>\left|b_{v} \hat{\mathrm{S}}_{v} / \hat{\boldsymbol{S}}\right|$ and (ii) the sign of $b_{j} \hat{S}_{j} / \hat{s}$ indicating whether $\mathrm{x}_{\mathrm{j}}$ and $\mathrm{y}$ tend to move in the same direction or in the opposite direction as long as the $\mathrm{x}_{\mathrm{j}}$ 's are independent.

The goodness of fit can be expressed as $\mathrm{R}^{2}$, given by the following formula:

$$
R^{2}=\frac{\sum_{i=1}^{n S}\left(\hat{y}_{i}-\bar{y}\right)^{2}}{\sum_{i=1}^{n S}\left(y_{i}-\bar{y}\right)^{2}}
$$

This provides a measure of variability about the regression model; the ratio provides a measure of the extent to which the regression model can match the observed data. Specifically, when the variation in the regression model is small, then the corresponding $\mathrm{R}^{2}$ value is close to 1 , which indicates that the regression model is accounting for most of the uncertainty in $\mathrm{y}$. Conversely, an $\mathrm{R}^{2}$ value close to 0 indicates that the regression model is not very successful in accounting for the uncertainty in y.

A rank transformation can be used to convert a nonlinear but monotonic relationship between the $\mathrm{x}_{\mathrm{j}}$ and $\mathrm{y}$ into a linear relationship. With this transformation, the values for the $\mathrm{x}_{\mathrm{j}}$ and $\mathrm{y}$ are replaced by their corresponding ranks. Specifically, the smallest value for a variable is assigned a rank of 1 , the next largest value is assigned a rank of 2, tied values are assigned their average rank, and so on, up to the largest value, which is assigned a rank of $\mathrm{nS}$. In the presence of non-linear but monotonic relationships between the $\mathrm{x}_{\mathrm{j}}$ and $\mathrm{y}$, use of the rank transformation can substantially improve the resolution of sensitivity analysis results. In the present study the Equations (3) and (4) are transformed into ranks, and a computer program was developed to estimate the Standardised Rank Regression Coefficients (SRRCs) and $\mathrm{R}^{2}$ values. Table 2 shows the SRRCs for 6 selected figures-of-merit against each of the 10 uncertain input parameters. $\mathrm{R}^{2}$ values are also shown in the table. The figures-of-merit considered are pressure at 170 minutes (Y1) and 180 minutes (Y2), rate of change in primary pressure after PORV closure (computed over 144 to 153 minutes) [Y3], hydrogen generation at the end of the calculation (Y4), intact fuel fraction at the time of re-flood (Y5) and RPV water level (Y6) at the time of reflood. The output parameter/figure-of-merit pressure at 170 and 180 minutes were selected because these timings were before and after reflood, respectively, and to see whether the prediction captured the observed values. Similarly, the rate of change in the primary pressure after PORV closure was selected to check whether pressure rises at the rate which was observed. The amount of hydrogen 
generated at the end of the calculation is obviously an important parameter. During the reflood, the clad may be shattered and therefore it is particularly interesting to know the intact fuel fraction and the level in the RPV.

\subsection{Partial Correlation}

Correlation provides a measure of the strength of the linear relationship between $\mathrm{x}_{\mathrm{j}}$ and $\mathrm{y}$. Specifically, the correlation coefficient (CC) between $\mathrm{x}_{\mathrm{j}}$ and $\mathrm{y}$ is defined by

$$
c\left(x_{j}, y\right)=\frac{\sum_{i=1}^{n S}\left(x_{i j}-\bar{x}_{j}\right)\left(y_{i}-\bar{y}\right)}{\left[\sum_{i=1}^{n S}\left(x_{i j}-\bar{x}_{j}\right)^{2}\right]^{1 / 2}\left[\sum_{i=1}^{n S}\left(y_{i}-\bar{y}\right)^{2}\right]^{1 / 2}}
$$

The $\mathrm{CC}$ has a value between -1 and 1 , with a positive value indicating that $\mathrm{x}_{\mathrm{j}}$ and $\mathrm{y}$ tend to increase and decrease together, and a negative value indicating that $\mathrm{x}_{\mathrm{j}}$ and $\mathrm{y}$ tend to move in opposite directions. Further gradations in the absolute value of CC between 0 and 1 correspond to a trend from no linear relationship between $\boldsymbol{x}_{j}$ and $\boldsymbol{y}$ to an exact linear relationship between $\boldsymbol{x}_{j}$ and $\boldsymbol{y}$.

The partial correlation coefficient (PCC) between $x_{j}$ and y can be defined in the following manner. First, the two regression models indicated below are constituted:

$$
\hat{x}_{j}=c_{0}+\sum_{\substack{p=1 \\ p \neq j}}^{n X} c_{p} x_{p} \text { and } \hat{y}=b_{0}+\sum_{\substack{p=1 \\ p \neq j}}^{n X} b_{p} x_{p}
$$

Then, the results of the two preceding regressions are used to define the new variables $\boldsymbol{x}_{j}-\hat{x}_{j}$ and y $-\hat{y}$. The PCC

Table 2. Standardised Rank Regression Co-efficients and $\mathrm{R}^{2}$

\begin{tabular}{c|c|c|c|c|c|c}
\hline Parameter & Y1 & Y2 & Y3 & Y4 & Y5 & Y6 \\
\hline $\mathrm{X} 1$ & -0.36 & -0.5 & -0.26 & -0.49 & 0.39 & 0.70 \\
\hline $\mathrm{X} 2$ & 0.44 & 0.48 & 0.58 & 0.51 & -0.46 & -0.43 \\
\hline $\mathrm{X} 3$ & -0.06 & -0.08 & -0.16 & -0.14 & -0.12 & 0.05 \\
\hline $\mathrm{X} 4$ & -0.1 & -0.23 & -0.02 & -0.17 & 0.28 & 0.10 \\
\hline $\mathrm{X} 5$ & 0.05 & 0.08 & -0.002 & 0.02 & 0.04 & 0.11 \\
\hline $\mathrm{X} 6$ & 0.2 & 0.03 & 0.19 & 0.07 & -0.13 & -0.15 \\
\hline $\mathrm{X} 7$ & -0.12 & -0.02 & -0.18 & -0.1 & -0.15 & 0.04 \\
\hline $\mathrm{X} 8$ & -0.32 & -0.21 & -0.30 & -0.12 & 0.3 & 0.16 \\
\hline $\mathrm{X} 9$ & 0.14 & 0.16 & 0.22 & 0.15 & -0.15 & -0.08 \\
\hline $\mathrm{X} 10$ & -0.12 & -0.2 & -0.15 & -0.17 & 0.07 & 0.01 \\
\hline & & & & & & \\
\hline $\mathrm{R}^{2}$ & 0.55 & 0.66 & 0.66 & 0.63 & 0.62 & 0.76 \\
\hline
\end{tabular}

between $\mathrm{x}_{\mathrm{j}}$ and $\mathrm{y}$ is the $\mathrm{CC} \mathrm{c}\left(\mathrm{x}_{\mathrm{j}}-\hat{x}_{j}, \mathrm{y}-\hat{y}\right)$ between $\mathrm{x}_{\mathrm{j}}-\hat{x}_{j}$ and $\mathrm{y}-\hat{y}$. The equations are also transformed into ranks and results in a partial rank correlation coefficient (PRCC). A separate computer program was developed to estimate the PRCCs for the selected figures-of-merit and uncertain input parameters. The PRCCs and SRRCs essentially give the same meaning when using ranks; the numerical values may be different but both exhibit the same pattern of sensitivity ranking. The benefit of using PRCCs is that they tend to be more spread out in value than SRRCs, thus producing results that are easier to read. The downside to this, however, is that a variable can appear to have a larger effect on the uncertainty in $\boldsymbol{y}$ than is actually the case. The PRCCs obtained using the above program are shown in Table 3.

The SRRCs and PRCCs are shown in Tables 2 and 3 respectively. They exhibit the same pattern of sensitivity rankings; however, the numerical values are different. The most important input parameters are shaded gray for each figure-of-merit. The first two input variables, i.e., make-up flow rate and PORV discharge coefficient, have a strong relationship with the figures-of-merit. The other input variables do not have strong relations with the figures-of-merit.

The calculation performed with the median inputs (shown in Figures 1 through 9) is not the one that yields the best agreement with the plant data. After reviewing the results of all 50 samples, it is found that the sample number (run) 33 shows the best agreement with the plant data. The input parameters for sample \#33 are as follows: $\mathrm{X} 1=2.52, \mathrm{X} 2=0.999, \mathrm{X} 3=2580, \mathrm{X} 4=0.264, \mathrm{X} 5=$ $0.375, \mathrm{X} 6=6.58 \mathrm{E}-02, \mathrm{X} 7=6.27 \mathrm{E}-02, \mathrm{X} 8=0.202, \mathrm{X} 9=$ 0.172 and $X 10=0.193$. Figure 10 shows the time history of the primary pressure of the sample \# 33 calculation and the plant data. About $450 \mathrm{~kg}$ of hydrogen is generated at

Table 3. Partial Rank Correlation Coefficients and $\mathrm{R}^{2}$

\begin{tabular}{c|c|c|c|c|c|c}
\hline Parameter & Y1 & Y2 & Y3 & Y4 & Y5 & Y6 \\
\hline $\mathrm{X} 1$ & -0.47 & -0.65 & -0.40 & -0.63 & 0.54 & 0.82 \\
\hline $\mathrm{X} 2$ & 0.55 & 0.65 & 0.71 & 0.66 & -0.61 & -0.68 \\
\hline $\mathrm{X} 3$ & -0.093 & -0.094 & -0.24 & -0.20 & -0.21 & 0.04 \\
\hline $\mathrm{X} 4$ & -0.15 & -0.34 & -0.025 & -0.25 & 0.40 & 0.16 \\
\hline $\mathrm{X} 5$ & 0.075 & 0.11 & -0.05 & -0.01 & 0.09 & 0.24 \\
\hline $\mathrm{X} 6$ & 0.29 & 0.025 & 0.28 & 0.09 & -0.18 & -0.29 \\
\hline $\mathrm{X} 7$ & -0.17 & -0.005 & -0.25 & -0.11 & -0.27 & 0.06 \\
\hline $\mathrm{X} 8$ & -0.43 & -0.26 & -0.41 & -0.13 & 0.38 & 0.24 \\
\hline $\mathrm{X} 9$ & 0.2 & 0.18 & 0.30 & 0.16 & -0.15 & -0.06 \\
\hline $\mathrm{X} 10$ & -0.18 & -0.36 & -0.27 & -0.30 & 0.14 & 0.07 \\
\hline & & & & & &
\end{tabular}




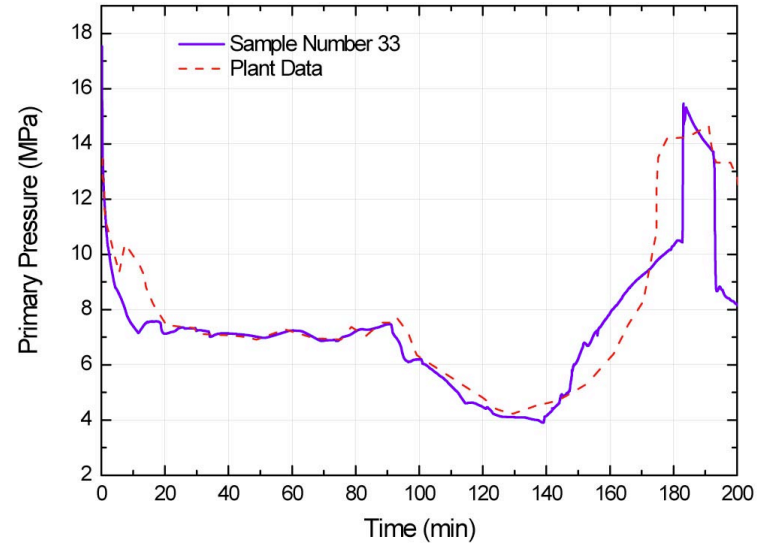

Fig. 10. Primary Pressure: Uncertainty Run Selected for Agreement with Plant Data

174 minutes, and $530 \mathrm{~kg}$ at the end of the calculation (200 minutes), compared to the estimated data of $300 \mathrm{~kg}$ and $460 \mathrm{~kg}$ of hydrogen generation, respectively.

\section{CONCLUSIONS}

The uncertainty and sensitivity analyses were carried out using simulation based methods in the present study. The Latin Hypercube Sampling technique was used for generating design matrix for code calculations. Fifty code calculations were performed in this analysis. This methodology systematically provided the insights related to uncertainties that exist in various models, initial and boundary conditions, etc. This methodology also gave insights into the identification of significant contributors. Parameters such as primary pressure, structure temperatures and hydrogen generation could be captured in the error bands between the $5^{\text {th }}$ and $95^{\text {th }}$ percentiles during most of the transient.

The sensitivity analysis results are described in the form of standardized rank regression coefficients (SRRCs) and partial rank correlation coefficients (PRCCs) in this study. The key figures of merit selected in this study are primary pressure before and after re-flood, rate of pressurization from 144 to 153 minutes, final hydrogen, intact fuel fraction just before re-flood, and RPV water level just before re-flood. The input parameters make-up flow rate during 100 to 200 minutes and PORV discharge coefficient (0.95 to 1.0) are found to be most important for the selected figures of merit.

\section{ACKNOWLEDGMENTS}

We sincerely acknowledge USNRC for providing data and for constant interactions throughout the analysis.

\section{NOMENCLATURE}

$\begin{array}{ll}\mathrm{b} & \text { Regression coefficients } \\ \mathrm{CC} & \text { Correlation Coefficient } \\ \mathrm{k} & \text { Number of input variables } \\ \mathrm{N} & \text { Ordered values } \\ \mathrm{n} & \text { Number of code runs } \\ \mathrm{nX} & \text { Number of uncertain input parameters } \\ \mathrm{PRCC} & \text { Partial Rank Correlation Coefficients } \\ \mathrm{SRCC} & \text { Standardised Rank Regression Coefficients } \\ \mathrm{p} & \text { percentile } \\ \mathrm{r} & \text { rank } \\ \mathrm{X} & \text { Input variables } \\ \mathrm{X} & \text { Uncertain analysis inputs } \\ \mathrm{y} & \text { Figure of merits }\end{array}$

\section{REFERENCES}

[ 1 ] J. C. Helton et al., "Survey of Sampling-based Methods for Uncertainty and Sensitivity Analysis", Reliability Engineering and System Safety, Volume 91, 1175-1209 (2006).

[2] IAEA safety report series, 2008, "Best Estimate Safety Analysis for Nuclear Power Plants: Uncertainty Evaluation", IAEA, Vienna.

[3 ] M. Khatib-Rahbar and M. J. Zavisca, "An Overview of the Three Mile Island Unit 2 Accident and Plant Design", Energy Research Inc., Maryland (November 2006).

[ 4 ] M. L. Corradini et al., "SCDAP/RELAP5 Independent Peer Review", Los Alamos National Laboratory, Las Alamos, LA-12481, UC-000 (January 1993).

[ 5 ] M. Khatib-Rahbar, E. Cazzoli, M. Lee, H. Nourbakhsh, R. Davis and E. Schmidt, "A Probabilistic Approach to Quantifying Uncertainties in the Progression of Severe Accidents", Nuclear Science \& Engineering, Volume 102, 219-259 (1989).

[6] SCDAP/RELAP5/MOD3.2 CODE MANUAL, VOLUME V, The SCDAP/RELAP5 Development Team, October 1997, Idaho National Engineering and Environmental Laboratory Lockheed Martin Idaho Technologies Idaho Falls, Idaho 83415

[ 7 ] M. Khatib-Rahbar et. al, "Analysis of Uncertainties Associated with the MELCOR Prediction of the TMI-2 Accident", Presentation made in Meeting of NRC/AERB, Mumbai, India (February, 2008).

[ 8 ] SCDAP/RELAP5/MOD3.2 CODE MANUAL, VOLUME II, The SCDAP/RELAP5 Development Team, October 1997, Idaho National Engineering and Environmental Laboratory Lockheed Martin Idaho Technologies Idaho Falls, Idaho 83415.

[9] Sang-Ryeol Park et al., "Development of an Uncertainty Quantification Method of the Best Estimate Large LOCA Analysis", Nuclear Engineering and Design, Volume 135, 367-378 (1992)

[10] D. M. Hamby, "A Review of Sensitivity Analysis Techniques (U)”, WSRC-MS-93-576, Westinghouse Savannah River Company, (March, 1994). 